\title{
The role of the Arabidopsis FUSCA3 transcription factor during inhibition of seed germination at high temperature
}

\author{
Rex S Chiu ${ }^{1,2}$, Hardeep Nahal ${ }^{2,3}$, Nicholas J Provart ${ }^{2,3}$ and Sonia Gazzarrini ${ }^{1,2^{*}}$
}

\begin{abstract}
Background: Imbibed seeds integrate environmental and endogenous signals to break dormancy and initiate growth under optimal conditions. Seed maturation plays an important role in determining the survival of germinating seeds, for example one of the roles of dormancy is to stagger germination to prevent mass growth under suboptimal conditions. The B3-domain transcription factor FUSCA3 (FUS3) is a master regulator of seed development and an important node in hormonal interaction networks in Arabidopsis thaliana. Its function has been mainly characterized during embryonic development, where FUS3 is highly expressed to promote seed maturation and dormancy by regulating ABA/GA levels.

Results: In this study, we present evidence for a role of FUS3 in delaying seed germination at supraoptimal temperatures that would be lethal for the developing seedlings. During seed imbibition at supraoptimal temperature, the FUS3 promoter is reactivated and induces de novo synthesis of FUS3 mRNA, followed by FUS3 protein accumulation. Genetic analysis shows that FUS3 contributes to the delay of seed germination at high temperature. Unlike WT, seeds overexpressing FUS3 (ML1:FUS3-GFP) during imbibition are hypersensitive to high temperature and do not germinate, however, they can fully germinate after recovery at control temperature reaching 90\% seedling survival. ML1:FUS3-GFP hypersensitivity to high temperature can be partly recovered in the presence of fluridone, an inhibitor of ABA biosynthesis, suggesting this hypersensitivity is due in part to higher ABA level in this mutant. Transcriptomic analysis shows that WT seeds imbibed at supraoptimal temperature activate seed-specific genes and ABA biosynthetic and signaling genes, while inhibiting genes that promote germination and growth, such as GA biosynthetic and signaling genes.

Conclusion: In this study, we have uncovered a novel function for the master regulator of seed maturation, FUS3, in delaying germination at supraoptimal temperature. Physiologically, this is important since delaying germination has a protective role at high temperature. Transcriptomic analysis of seeds imbibed at supraoptimal temperature reveal that a complex program is in place, which involves not only the regulation of heat and dehydration response genes to adjust cellular functions, but also the activation of seed-specific programs and the inhibition of germination-promoting programs to delay germination.
\end{abstract}

Keywords: High temperature, FUSCA3, Seed germination, Hormones, ABA, Transcriptome

\footnotetext{
* Correspondence: gazzarrini@utsc.utoronto.ca

'Department of Biological Sciences, University of Toronto, 1265 Military Trail,

Toronto, ON, M1C 1A4 Canada

Full list of author information is available at the end of the article
} 


\section{Background}

Seed maturation begins during mid-embryogenesis and controls important traits, including seed quality and viability. In Arabidopsis, during mid-embryogenesis the embryo accumulates storage compounds, such as seed storage proteins (SSP) and lipids, which are broken down during the first days of germination to sustain the growing seedling. As development progresses into late embryogenesis a variety of protective proteins, including late embryogenesis abundant proteins (LEA) and heat shock proteins (HSP), are synthesized to prepare the embryo for desiccation and the final stage of dormancy [1]. Genetic and molecular studies have shown that seed maturation is orchestrated by the hormone abscisic acid $(\mathrm{ABA})$ and a network of transcription factors, which include the LEAFY COTYLEDON1 (LEC1) CCAAT binding factor and the B3-domain transcription factors, LEC2, FUSCA3 (FUS3) and ABSCISIC ACID INSENSITIVE3 (ABI3) [2-4]. These genes are considered global regulators of seed maturation, as loss-of-function mutant embryos skip late-embryonic development and enter the vegetative program prematurely. As a consequence, immature mutant seeds are less dormant, can germinate precociously and accumulate less seed storage compounds. Furthermore, seeds of fus 3 , abi3 and lec1 mutants are also desiccation intolerant and become inviable when dry [5-11]. Enhancement of these phenotypes shown in higher order mutants, and in transcriptional regulatory studies, demonstrates that these genes act in concert to control seed maturation, dormancy and desiccation tolerance [8-10,12-14]. The important role of $A B A$ in regulating seed maturation and dormancy is exemplified by genetic and chemical studies, which show that a reduction of $\mathrm{ABA}$ level also decreases seed dormancy $[3,15]$. Further studies have shown that B3-domain transcription factors are important nodes in hormone signaling pathways and control important steps in hormone biosynthesis. For example, FUS3 promotes dormancy and prevents precocious germination of immature seeds, by stimulating ABA synthesis while repressing GA biosynthesis [16-18]. In a feedback regulation, $A B A$ and GA respectively stabilize and destabilize the FUS3 protein through a mechanism involving the $\mathrm{C}$-terminal region of FUS3 $[17,19]$. In addition to its role in seed development, $A B I 3$ is a positive regulator of ABA signaling, as abi3 seeds are strongly insensitive to $A B A$ during germination $[5,6,20]$. ABA sensitivity is not affected in fus3, lec1 and lec2, suggesting that $\mathrm{ABA}$ sensitivity and seed maturation can be uncoupled $[9,10]$. The B3-domain proteins are also involved in auxin sensitivity and biosynthesis. The promoters of FUS 3 and $A B I 3$ are induced by auxin, while auxin biosynthetic genes are positively regulated by $L E C 2$ and FUS3 [17,21-23].
The B3-domain binds the Sph/RY (CATGCA) core element found in the promoter of many seed-specific genes and some of the B3-domain targets include $L E A$ and $E m$ [24-26]. These genes are also under the control of ABA [27]. RY/Sph elements have been shown to act synergistically with $A B A$ response elements (ABRE), suggesting that a complex interaction of seed-specific and ABAregulated factors controls late embryogenesis and seed maturation [28-30]. Heat shock factors (HSF) and HSPs, which are rapidly induced during heat stress (HS) and highly abundant in seeds, are also B3-domain and ABA targets. In particular, the expression of the seed specific HSFA9 is induced by $A B I 3$ through the Sph/RY in an ABA-dependent manner. Activation of HSFA9, in turn, regulates the expression of select $H S$ genes [31].

Transcript levels of the $L E C$, FUS3 and ABI3 genes are abundant during embryogenesis, decrease during germination, and are expressed at low levels in vegetative organs [13,19,32-34]. Repression of these genes during germination is required to enter vegetative development, as overexpression of FUS3 and the LEC post-embryonically results in the expression of embryonic markers and the development of embryonic structures during vegetative growth [17,33,35-37]. More specifically, overexpression of FUS3 (ML1:FUS3-GFP) results in delayed seed germination and hypersensitivity to ABA. Since one of the roles of dormancy is to stagger germination and prevent mass growth under suboptimal conditions, we tested whether during imbibition under abiotic stress FUS3 would be re-activated to delay germination. Among the stresses tested in this study, we found that high temperature induces de novo FUS3 mRNA synthesis and protein accumulation in imbibed seeds. In contrast to WT, ML1:FUS3-GFP seeds overexpressing FUS3 during germination are hypersensitive to supraoptimal (high) temperature and fail to germinate. Inhibition of ML1:FUS3-GFP germination at supraoptimal temperature is partly dependent on ABA biosynthesis and is a reversible process, as ML1:FUS3-GFP seeds imbibed at high temperature for six days can resume germination when the temperature becomes optimal for growth. Transcriptomic analysis shows that seeds exposed to supraoptimal temperature re-activate the expression of late embryonic and seed maturation programs, while inhibiting germination-promoting programs, to delay seed germination at supraoptimal temperatures.

\section{Results}

Germination at supraoptimal temperature activates the FUS3 promoter and induces FUS3 mRNA and protein accumulation

To test whether FUS3 plays a role during germination under abiotic stresses, we measured FUS3 mRNA levels 
in WT seeds imbibed on high salt $(150 \mathrm{mM} \mathrm{NaCl})$, during osmotic stress $\left(300 \mathrm{mM}\right.$ mannitol) and at low $\left(12^{\circ} \mathrm{C}\right)$ and high $\left(32^{\circ} \mathrm{C}\right)$ temperatures (Figure 1$)$. These conditions have been previously shown to delay WT seed germination [38]. We screened for changes in patterns of FUS3 expression at early ( 3 or $6 \mathrm{~h}$ ) and late ( 24 or $48 \mathrm{~h}$ ) stages of seed imbibition, since FUS3 transcript level rapidly decreases during germination [19]. FUS3 mRNA level is only slightly affected on $150 \mathrm{mM} \mathrm{NaCl}$ and fluctuates in expression on $300 \mathrm{mM}$ mannitol and at $12^{\circ} \mathrm{C}$. In contrast, FUS3 mRNA level increases 2-4 fold in seeds imbibed at $32^{\circ} \mathrm{C}$ for $24 \mathrm{~h}$ and $48 \mathrm{~h}$, therefore, we investigated the role of FUS3 during seed germination at high temperature in more detail.

We performed a more detailed time-course experiment and monitored FUS3 expression level in seeds imbibed at $32^{\circ} \mathrm{C}$ for up to 3 days (Figure 2A). We found that the level of FUS3 mRNA decreases faster during the first $3 \mathrm{~h}$ of $\mathrm{HS}$, reaching a comparable level to the control at $6 \mathrm{~h}$. Thereafter, the mRNA starts increasing and remains higher than the control for at least 3 days (Figure 2A). To test whether the increase in FUS3 mRNA after longer HS exposure was due to an activation of the FUS3 promoter or an increase in FUS3 mRNA stability, we used the FUS3:GFP transcriptional reporter previously described (Figure 2B) [19]. Compared to the $21^{\circ} \mathrm{C}$ control, there is a marked increase in GFP fluorescence at $32^{\circ} \mathrm{C}$ between 24 and $72 \mathrm{~h}$, which reflects an increase in FUS3 promoter activity. Thus, the

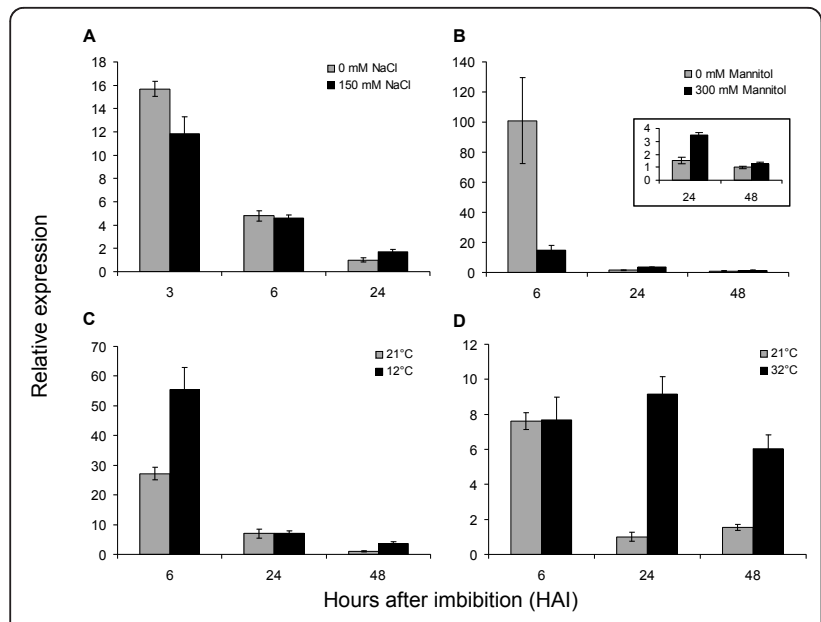

Figure 1 Transcriptional regulation of FUS3 by abiotic stresses (A-D) Relative FUS3 mRNA levels measured by qPCR in mature seeds exposed to abiotic stresses during imbibition under constant light. A) salt, $150 \mathrm{mM} \mathrm{NaCl}$; B) osmotic, $300 \mathrm{mM}$ mannitol; C) low temperature, $12^{\circ} \mathrm{C}$ and D) high temperature, $32^{\circ} \mathrm{C}$. The mean value of three replicates was normalized using ACTIN 7 as the internal control. Results are plotted as the ratio to the lowest detected level. Two independent experiments were conducted with similar results and one representative is shown. exposure of seeds to high temperatures induces rapid degradation of FUS3 mRNA within the first $3 \mathrm{~h}$, followed by transcriptional activation (or derepression) leading to new mRNA synthesis from $12 \mathrm{~h}$. These findings are mirrored by an increase in FUS3 protein level, measured by using the FUS3:FUS3-GFP (FFG) translational reporter previously described (Figure 2C, D) [17]. The FUS3-GFP protein was detected in the nuclei of epidermal cells and on immunoblots of seeds imbibed at $32^{\circ} \mathrm{C}$ for 48 and $72 \mathrm{~h}$ (Figure 2C, D). In agreement with previous studies, no FUS3-GFP was detected in seeds imbibed at $21^{\circ} \mathrm{C}$ for up to 3 days (Figure 2C, D) [19].

Next, we tested whether the late accumulation of the FUS3-GFP protein at $32^{\circ} \mathrm{C}$ was due to an increase in the seed ABA/GA ratio, as Arabidopsis seeds imbibed at high temperature repress GA biosynthesis and induce de novo ABA synthesis resulting in a higher ABA level at 24 h [39]. No FUS3-GFP was detected in FUS3:FUS3GFP seeds germinated on ABA or paclobutrazol, a GA biosynthesis inhibitor, at $21^{\circ} \mathrm{C}$, suggesting that FUS3 accumulation at high temperature is not dependent solely on higher ABA level (Additional file 1). Interestingly, the FUS3 protein was detected only in seeds that have commenced germination (radicle protrusion), but not in thermoinhibited seeds (no radicle protrusion) or seedlings that have germinated from the seed coat. This suggests that during germination at high temperature, FUS3 may act in a small developmental window that precedes seedling emergence from the seed coat. Together, these results indicate that imbibition at the supraoptimal temperature of $32^{\circ} \mathrm{C}$ induces an increase in FUS3 transcript level at $12-24 \mathrm{~h}$, which is followed by an increase in FUS3 protein level at $48 \mathrm{~h}$.

\section{Seed germination and seedling survival of WT and fus3 loss- and gain-of-function mutants imbibed at high temperature}

To dissect the role of FUS3 during germination at supraoptimal temperatures, we monitored the germination and survival rates of WT, fus 3 loss-of-function (fus3-3) and overexpression (fus3-3, ML1:FUS3-GFP) mutant seeds imbibed at $32^{\circ} \mathrm{C}$ (Figure 3). The $M L 1$ : FUS3-GFP construct was previously shown to rescue the fus3-3 loss-of-function mutant and overexpress FUS3 post-embryonically throughout vegetative and reproductive development [17]. At $21^{\circ} \mathrm{C}$, mature WT seeds reach $100 \%$ germination within 2 days, while ML1:FUS3-GFP seeds are more dormant and germinate slower reaching $90 \%$ germination in 5-6 days (Figure 3A). Despite reaching $60-100 \%$ germination within 6 days (depending on seed batches), mature WT seeds show delayed germination at $32^{\circ} \mathrm{C}$ (Figure 3B). All grown seedlings manifest phenotypes associated with high temperature stress, including arrested growth and bleached cotyledons and 
A

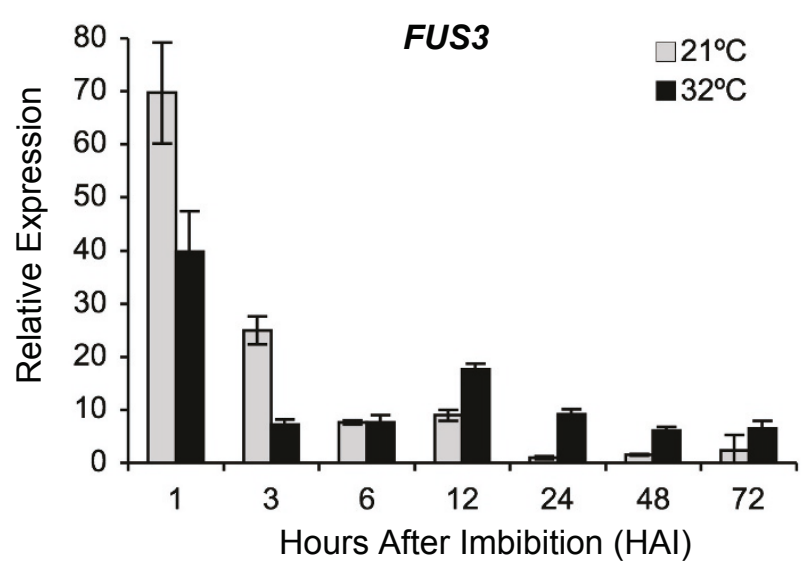

B

FUS3:GFP

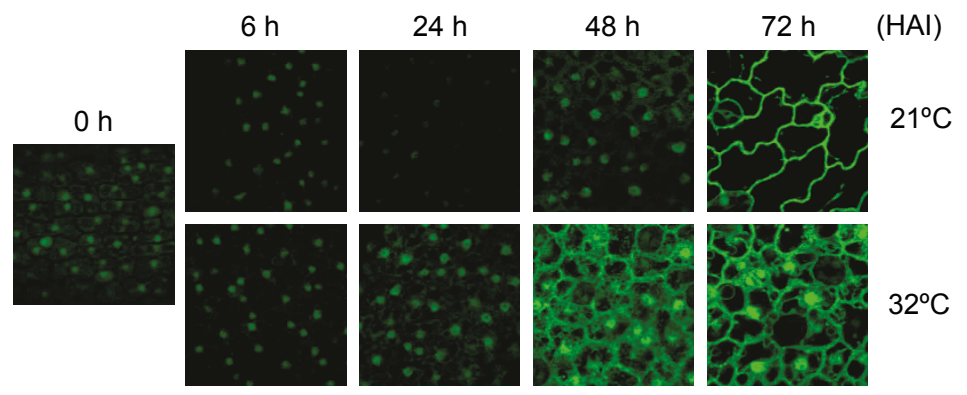

C

FUS3:FUS3-GFP (FFG)

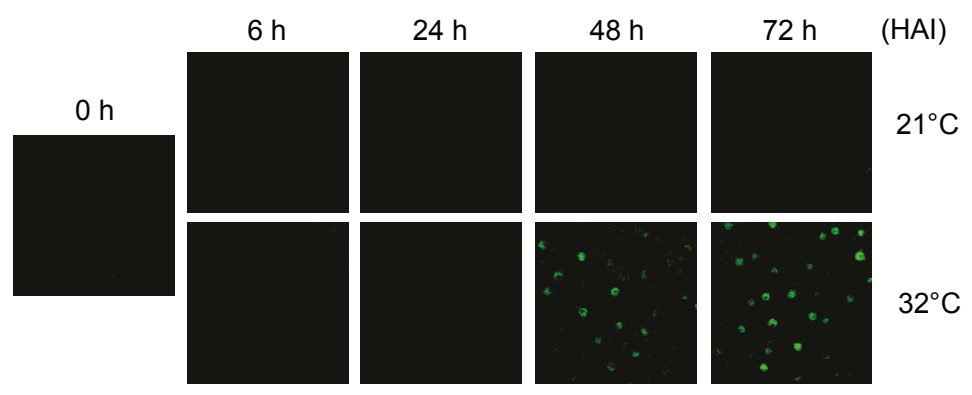

D

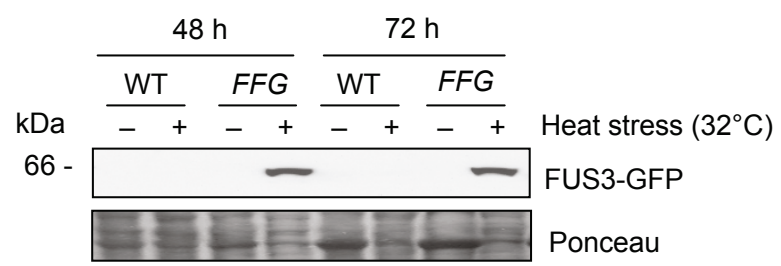

Figure 2 Seed imbibition at supraoptimal temperature activates the FUS3 promoter and induces de novo FUS3 mRNA synthesis and FUS3 protein accumulation. (A) Relative FUS3 mRNA levels measured by $9 P C R$ in seeds imbibed at $21^{\circ} \mathrm{C}$ or $32^{\circ} \mathrm{C}$ for up to $72 \mathrm{~h}$ under constant light. The mean value of three replicates was normalized using ACTIN 7 as the internal control. Results are plotted as the ratio to the lowest detected level. Two independent experiments were conducted with similar results and one representative is shown. (B) Confocal images showing GFP fluorescence in the epidermis of FUS3:GFP embryos of seeds imbibed at $21^{\circ} \mathrm{C}$ or $32^{\circ} \mathrm{C}$. HAl, hours after imbibition. (C, D) Confocal images (C) and immunoblots (D) showing FUS3-GFP fluorescence and protein accumulation in FUS3p:FUS3-GFP (FFG) seeds imbibed at $21^{\circ} \mathrm{C}$ and $32^{\circ} \mathrm{C}$ for up to $72 \mathrm{~h}$ under constant light. WT in D) is shown as the negative control. FUS3-GFP ( MW $\left.61 \mathrm{kDa}\right)$ was detected with anti-GFP antibody. Comparable confocal settings were used in all images shown in B) and C). Duplicate experiments were conducted and one representative is shown. 
A

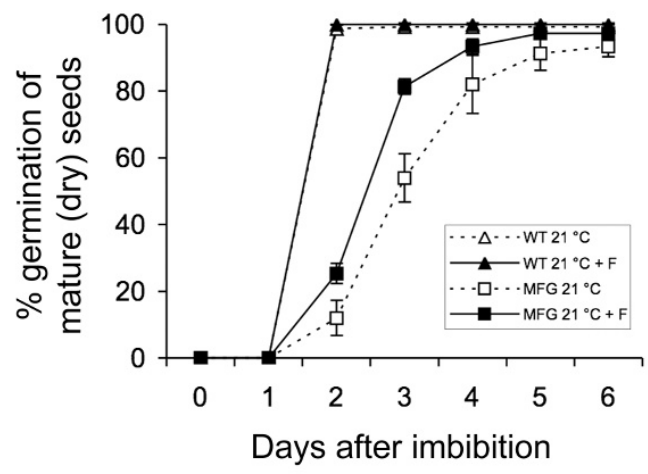

C

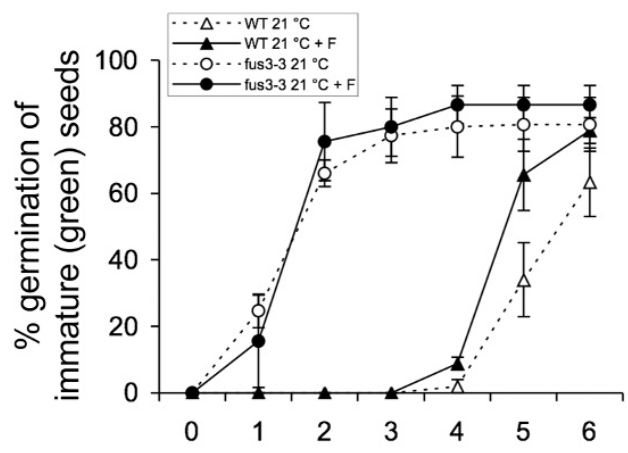

Days after imbibition
B

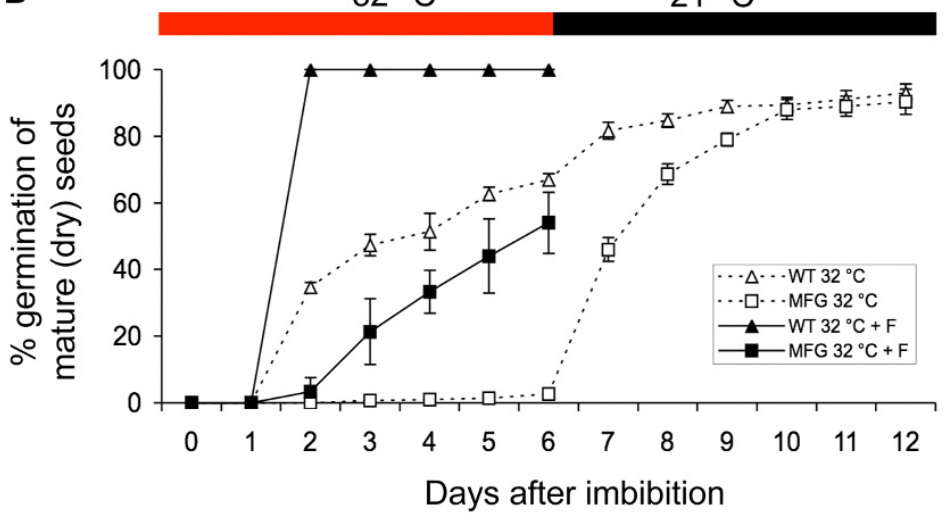

D

$32{ }^{\circ} \mathrm{C}$ $21^{\circ} \mathrm{C}$

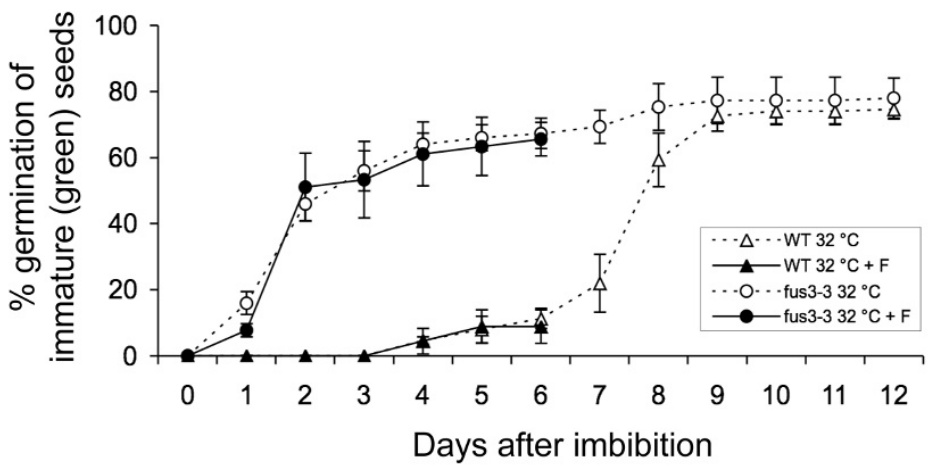

G

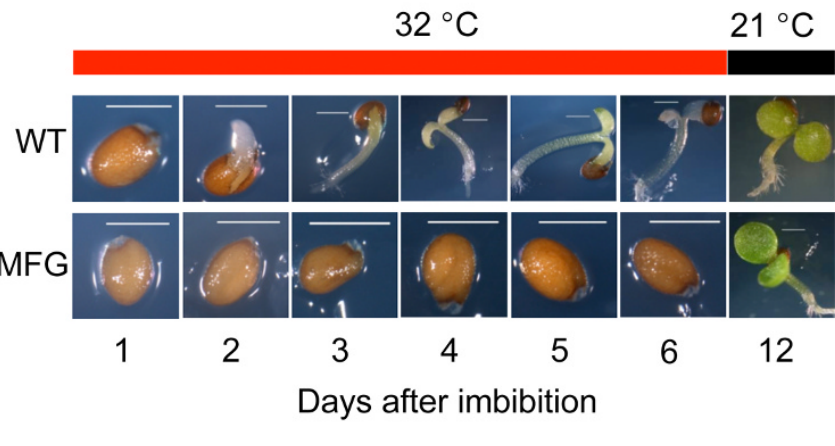

Figure 3 Germination rates and seedling survival of FUS3 loss- and gain-of-function mutants during imbibition at supraoptimal temperature and recovery after heat stress. (A-G) Germination rates and\% of seedlings survival of wild type (WT), FUS3 loss-of-function mutant (fus3-3) and ML1:FUS3-GFP (MFG) gain-of-function mutant during imbibition at control $\left(21^{\circ} \mathrm{C}\right)$ and supraoptimal temperature $\left(32^{\circ} \mathrm{C}\right)$. (A, $\mathrm{B}$, E) Germination (radicle protrusion) rates of mature WT and MFG dry seeds imbibed on filter papers on MS plates in the absence or presence of $10 \mu \mathrm{M}$ fluridone $(+\mathrm{F})$ at $21^{\circ} \mathrm{C}(\mathrm{A})$ and $32^{\circ} \mathrm{C}(\mathrm{B})$. After six days of imbibition at $32^{\circ} \mathrm{C}$, plates in $\left.\mathrm{B}\right)$ were transferred to the control temperature $\left(21^{\circ} \mathrm{C}\right)$ for six additional days and the\% of seedlings survival (showing green cotyledon and green leaves) was calculated in (E). (C, D, F) Germination (radicle protrusion) rates of immature WT and fus3-3 green seeds imbibed on filter papers on MS media in the presence or absence of $10 \mu \mathrm{M}$ fluridone $(+F)$ at $21^{\circ} \mathrm{C}(\mathrm{C})$ and $32^{\circ} \mathrm{C}(\mathrm{D})$. After six days of imbibition at $32^{\circ} \mathrm{C}$, plates in D) were transferred to the control temperature $\left(21^{\circ} \mathrm{C}\right)$ for six additional days and the\% of seedlings survival (showing green cotyledon and green leaves) was calculated in (F). (G) Appearance of representative WT and MFG seeds from the experiment shown in B). Averages from triplicates \pm s.d. are shown ( $n \geq 300$ seeds). Experiments were repeated at least twice with similar results and one representative is shown. F, fluridone. Red bars, $32^{\circ} \mathrm{C}$. Black bars, $21^{\circ} \mathrm{C}$. 
hypocotyls (Figure 3G). These seedlings do not recover and fail to grow even when transferred to $21^{\circ} \mathrm{C}$, indicating that prolonged exposure to $32^{\circ} \mathrm{C}$ is lethal for Arabidopsis seedling growth (Figure $3 \mathrm{~B}, \mathrm{E}$ ). In contrast, germination of mature ML1:FUS3-GFP seeds was greatly reduced or inhibited (depending on seed batches) for up to 6 days at $32^{\circ} \mathrm{C}$, suggesting ML1:FUS3-GFP seeds are hypersensitive to high temperatures (Figure 3A, B, G). Although a very low percentage of seeds show radicle protrusion between 3 and 6 days, no seedling emerges from the seed coat (Figure 3B, G). Interestingly, all ML1:FUS3-GFP seeds resumed germination when transferred to the control temperature and this results in a much greater ML1:FUS3-GFP survival rate compared to the WT (Figure 3B, E).

Mature fus3 loss-of-function (fus3-3) mutant seeds are desiccation intolerant and inviable, but can be rescued if immature seeds are harvested when still green, prior to desiccation. Therefore, we compared the germination rates of immature green seeds of fus3-3 and WT when imbibed under control and high temperature (Figure $3 \mathrm{C}$, D). At $21^{\circ} \mathrm{C}$, immature WT seeds begin to germinate 4 days after imbibition and reach $\sim 60 \%$ germination by 6 days. This is expected, as immature WT seeds are dormant. However, at $32^{\circ} \mathrm{C}$, immature WT seeds show strong thermoinhibition and reach $\sim 10 \%$ germination after 6 days. After transfer to $21^{\circ} \mathrm{C}$, WT immature seeds resume germination. In contrast, immature fus3-3 seeds reach $\sim 80 \%$ and $\sim 60 \%$ germination by 6 days at $21^{\circ} \mathrm{C}$ and $32^{\circ} \mathrm{C}$, respectively, and thus are strongly resistant to thermoinhibition. As expected, immature fus3-3 seeds, which have a higher percentage of germination than immature WT seeds at $32^{\circ} \mathrm{C}$, showed lower seedling survival than WT after recovery at $21^{\circ} \mathrm{C}$ (Figure $3 \mathrm{D}, \mathrm{F}$ ). In summary, this data indicates that overexpression of FUS3 inhibits seed germination at supraoptimal temperature and this increases seedling survival when temperatures become optimal for growth. It also suggests that inhibition of germination at supraoptimal temperature is a reversible process and has a protective role for the embryo.

\section{ML1:FUS3-GFP hypersensitivity to high temperature during imbibition is dependent on $A B A$ biosynthesis} Arabidopsis seeds imbibed at $34^{\circ} \mathrm{C}$ have higher ABA/GA ratio due to the activation of $\mathrm{ABA}$ and repression of $\mathrm{GA}$ biosyntheses, which results in thermoinhibition of seed germination [39]. ML1:FUS3-GFP seeds are hypersensitive to ABA during germination and transient activation of FUS3 using an ML1:FUS3-GR construct increases ABA levels post-embryonically [17]. In light of this, we investigated whether ML1:FUS3-GFP inhibition of germination at $32^{\circ} \mathrm{C}$ is due to altered ABA biosynthesis. To test this, we germinated WT and ML1:FUS3-GFP seeds in the presence of fluridone, an inhibitor of ABA biosynthesis. Fluridone can fully reverse the delay of WT germination at $32^{\circ} \mathrm{C}$ and partly recover the inhibition of ML1:FUS3-GFP germination at $32^{\circ} \mathrm{C}$ (Figure 3B). Fluridone also increases the germination rate of ML1:FUS3GFP seeds at $21^{\circ} \mathrm{C}$ (Figure $3 \mathrm{~A}$ ). This suggests that the delayed germination of ML1:FUS3-GFP seeds at the control temperature, and inhibition at high temperature, appear to be partly dependent on de novo ABA biosynthesis. Furthermore, since seeds overexpressing FUS3 are more dormant, partly due to increased ABA biosynthesis, increased dormancy may have a positive effect during germination at supraoptimal temperatures.

In contrast, fluridone did not have any effect on the germination of immature fus3-3 and WT seeds at $32^{\circ} \mathrm{C}$, and slightly increased the germination of WT seeds at $21^{\circ} \mathrm{C}$ (Figure 3C). The insensitivity of fus3-3 seeds to fluridone was expected, as fus3-3 seeds have a lower ABA level [16,17]. However, the lack of effect of fluridone on the germination of immature WT seeds was surprising. Since immature WT seeds resume germination when plates are shifted to the optimal temperature, the lack of effect of fluridone on WT germination cannot be attributed to damage or death of the WT green seeds. This suggests that de novo ABA synthesis may not have a predominant role in regulating the germination of WT immature seeds at high temperature (Figure $3 \mathrm{D}$ and $3 \mathrm{E})$.

\section{Transcriptomic analysis of seeds imbibed at high temperature}

Our data shows that seed germination at the supraoptimal temperature of $32^{\circ} \mathrm{C}$ induces de novo FUS3 mRNA synthesis and, most importantly, FUS3 protein accumulation. Furthermore, FUS3 overexpression strongly inhibits Arabidopsis germination partly through ABA biosynthesis. Since high temperature induces not only changes in ABA/GA levels but also reactivates FUS3 function in imbibed seeds, we predicted that high temperature would also activate seed maturation programs partly regulated by the B3-protein network to delay germination. Furthermore, since FUS3 controls the ABA/ $\mathrm{GA}$ ratio and since $\mathrm{ABA}$ and $\mathrm{GA}$ have been shown to play important roles during thermoinhibition, we were interested in identifying hormonal networks working at the time FUS3 is active. Therefore, we characterized the transcriptomic response of WT seeds imbibed at high temperature. We conducted a time-course microarray (Affymetrix ATH1) with WT Arabidopsis seeds imbibed at optimal $\left(21^{\circ} \mathrm{C}\right)$ or supraoptimal $\left(32^{\circ} \mathrm{C}\right)$ temperatures for 1,12 and $24 \mathrm{~h}$. These time points were chosen to identify early $(1 \mathrm{~h})$ and late (12 and $24 \mathrm{~h})$ heat-stress responsive $(H S R)$ genes. The latter time points were also chosen because they correlate with an increase in ABA 
level and FUS3 expression, and thus may identify FUS3 and $\mathrm{ABA}$ coexpressed genes.

Only a small set of 157 genes change in expression level after $1 \mathrm{~h}$ of heat treatment, while $>2000$ genes are differentially expressed at both 12 and $24 \mathrm{~h}$, indicating a large transcriptional reprogramming at later stages of HS (Figure 4; Additional files 2, 3, 4). While there is a relatively small overlap between early and late $H S R$ genes, a large number of genes show increased (677) or decreased (378) expression at both 12 and $24 \mathrm{~h}$. To determine the cellular responses to HS, we analyzed transcriptional changes using the Gene Ontology (GO) enrichment analysis (Additional files $5,6,7,8,9,10)[40]$. At all time points, the largest $\mathrm{GO}$-function categories being enriched are those comprising 'cellular and metabolic processes', while the most significant function being enriched is the 'response to stimulus' (Additional file 5). After $1 \mathrm{~h}$ of exposure to $32^{\circ} \mathrm{C}$ the imbibed seed has limited response, and genes important for the 'response to high temperature' and 'protein folding' are among the most enriched in early HSRs (Additional file 6). After

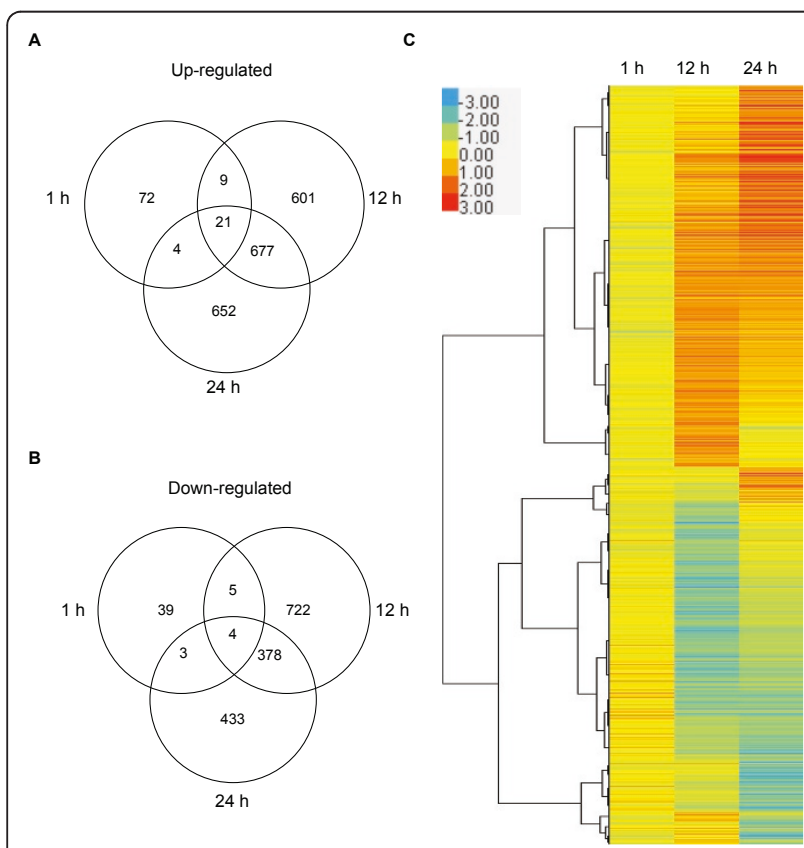

Figure 4 Cluster analysis of differentially expressed HSR genes. $(A, B)$ Venn diagrams showing the number of transcripts with enhanced (A) or decreased (B) expression levels in seeds imbibed for 1,12 and $24 \mathrm{~h}$ at $32^{\circ} \mathrm{C}$ compared to $21^{\circ} \mathrm{C}$. Only genes showing a minimum fold change $1.8\left(\log _{2} \geq 0.85\right)$ and a $p$-value $<0.05$ were selected. Results are presented as averages of two independent experiments. (C) Heat map of differentially expressed genes in seeds imbibed for 1,12 and $24 \mathrm{~h}$ at $32^{\circ} \mathrm{C}$ compared to $21^{\circ} \mathrm{C}$ based on hierarchical clustering. Red color indicates upregulated genes, blue color indicates downregulated genes and yellow color indicates genes whose expression is unchanged.
12 and $24 \mathrm{~h}$ of imbibition at $32^{\circ} \mathrm{C}$, however, the cellular response of the seed becomes more complex. GOenrichment analysis suggests that the specificity of the HS response is strengthened by activating genes required for thermotolerance, adjusting cellular metabolism and inhibiting growth and development (Additional files $7,8,9,10$ ). While the most significant biological function enriched in late HSRs is again the 'response to stimulus', 'embryonic development' and 'seed dormancy' are also among the GO-function categories significantly enriched (Additional files 7, 8, 9, 10). The most enriched 'stimuli' include abiotic (high temperature, oxidative, high light and water deprivation) and chemical (ABA, GA and auxin) stimuli.

\section{Stress-related and seed maturation genes are activated during seed imbibition at supraoptimal temperature} HSPs and HSFs are well known for their protective role in cellular functions at high-temperature and are rapidly induced after HS, however, they also play a role in other stresses [41]. Seven HSPs and four HSFs increase in expression at $1 \mathrm{~h}$, including HSFA2 and HSFA7, which have been well characterized for their role in the acquisition of thermotolerance in seedlings (Figure 5) $[42,43]$. A larger number of HSPs (49 genes) and HSFs (7 genes) show an increase in transcript abundance at $12 \mathrm{~h}$ and/or $24 \mathrm{~h}$, with a strong induction of the highly expressed HSFA 2 and the proposed seed-specific and HS-independent, HSFA9 (Figure 5) [31]. These late-induced HSF genes may be required for prolonged cellular responses to high temperature.

As expected, seeds imbibed at high temperature for 12 and 24 h show a large increase in the expression levels of late embryogenesis and seed maturation genes, including LEA, SSPS and storage lipids (42 genes; Figure 5). Together with molecular chaperones and other protective compounds, LEA genes are thought to be involved in direct abiotic stress tolerance and are induced by several abiotic stresses [41]. SSP and storage lipids are typical markers of seed maturation and some have been shown to be regulated directly or indirectly by B3-domain proteins, including FUS3 [6-10,13,23-26,28,37]. Among the known global regulators of late embryogenesis and seed maturation, FUS3 is the only gene induced by HS, suggesting that it may play an important role in the activation of seed-specific programs during imbibition at supraoptimal temperature (Additional file 4, Additional file 5). Interestingly, transcript levels of three yet uncharacterized B3-containing proteins (At4g33280, At2g35310, At5g25475) are also induced at $24 \mathrm{~h}$ (Additional file 5), and may play complementary roles with FUS3 during imbibition at supraoptimal temperature. 


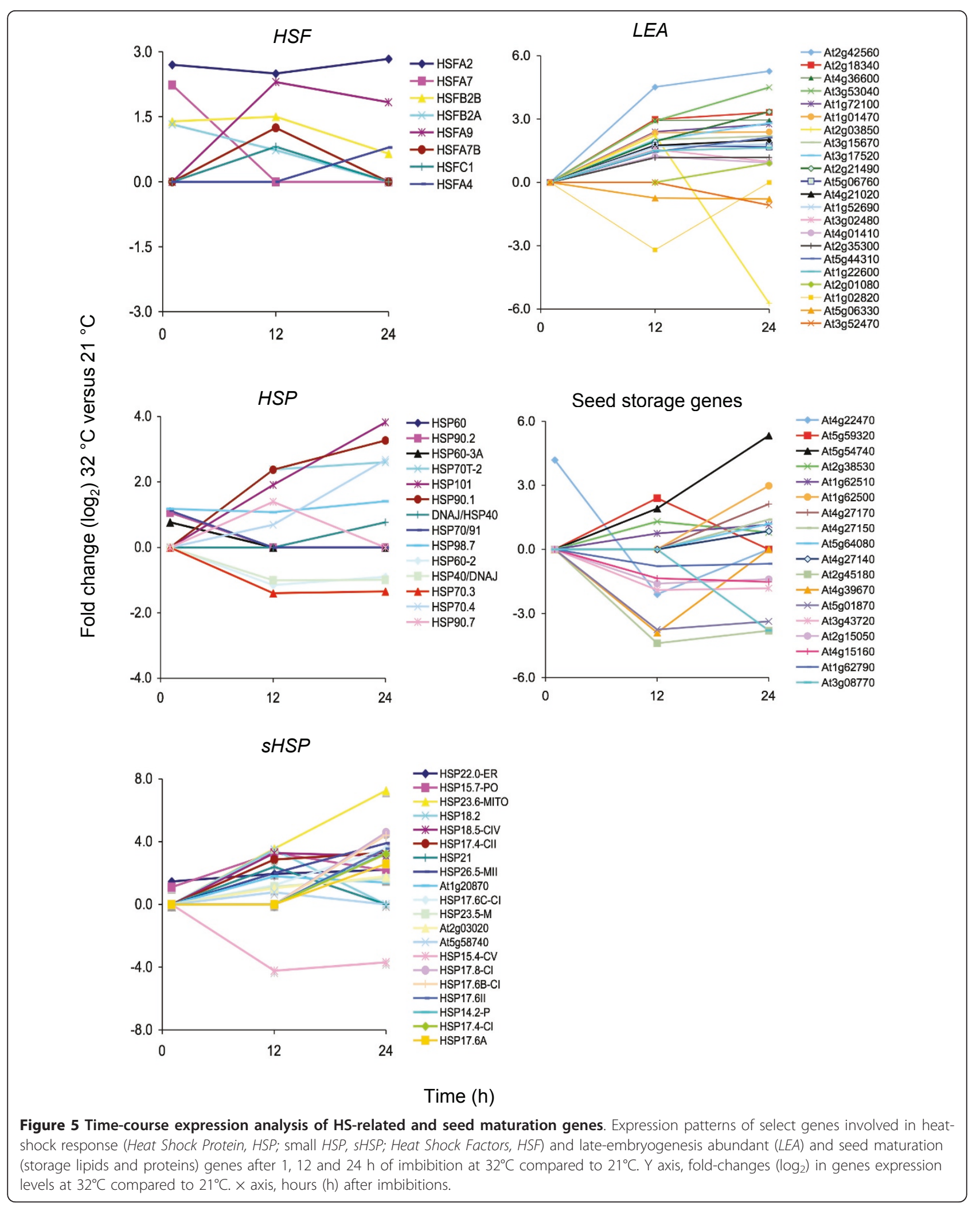




\section{Prolonged HS activates $\mathrm{ABA}$ and represses GA metabolic genes}

Genes involved in hormone metabolism and signaling, predominantly the hormones ABA and GA, are enriched among the late $H S R$ genes (Additional file 7, 8, 9, 10). Genes regulating ABA metabolic pathways show increased mRNA levels, while transcript levels of GA biosynthesis genes are decreased (Figure 6). Only a few known GA signaling genes were identified as $H S R$ in our microarray, including the GA receptor, GID1A, and signaling components such as $S P Y$ and $S L Y$. In contrast, several genes involved in ABA signaling are differentially expressed at high temperature. These include several members of the ABA receptor family ( $P Y L / R C A R s)$, as well as other downstream signaling components such as PP2C phosphatases (ABI1, HAI2, HAI3, AHG1) and transcription factors $(A B I 4, A B I 5)$ (Figure 6). More than 100 kinases have altered expression level during heat stress, including members of the $S n R K 2 / 3$ families of serine/threonine kinases, which comprises positive regulators of ABA signaling and abiotic stress responses (Additional file 3, Additional file 4) [44]. Most of these genes, including several PYL/RCARs, PP2Cs and SnRK2/ 3 kinases have uncharacterized functions. Thus, transcriptomic analysis of seeds imbibed at high temperature suggests that select known ABA signaling genes as well as uncharacterized members of the $P Y L / R C A R, P P 2 C$ and $S n R K$ families are differentially regulated during germination at supraoptimal temperature and may play specific roles during thermoinhibition.

A number of genes coding for different families of transcription factors involved in other hormone or stress

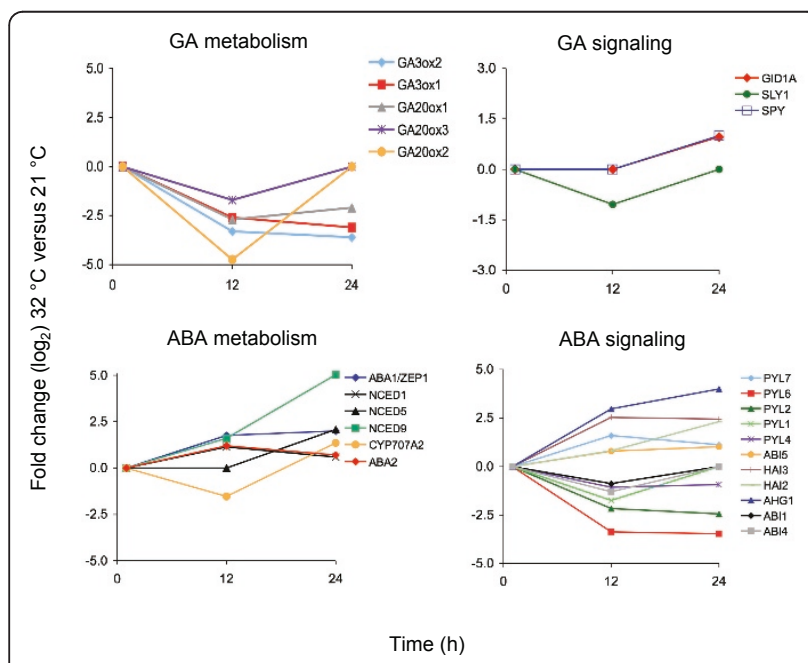

Figure 6 Time-course expression analysis of select HSR genes. Expression patterns of hormone ( $A B A$ and $G A$ ) metabolism and signaling genes after 1,12 and $24 \mathrm{~h}$ of imbibition at $32^{\circ} \mathrm{C}$ compared to $21^{\circ} \mathrm{C}$. $\mathrm{Y}$ axis, fold-changes $\left(\log _{2}\right)$ in genes expression levels at $32^{\circ}$ $\mathrm{C}$ compared to $21^{\circ} \mathrm{C} . \times$ axis, hours (h) after imbibitions. signaling pathways are also differentially regulated at 12 and $24 \mathrm{~h}$. Transcript levels of the drought and heatstress responsive DREB2A [45], auxin (ARF11, ARF18 and several SAUR) and ethylene (EIN3, EIN4, ERSs, $E R F S$ ) responsive genes are among some of those that fluctuate in expression level at 12 and/or 24 h (Additional file 3, Additional file 4). Thus, other hormones beside ABA and GA may play a role during germination at supraoptimal temperature.

\section{Core HSR genes}

The transcript levels of 25 genes are increased or decreased at all three time points and constitute the core HSR genes (Table 1). Beside the constitutively and highly expressed $H S F A 2$, all other genes in this list have not been tested for their role during HS. Interestingly, $P D X 1.2$ is highly expressed and is among the strongest $H S R$ genes induced at $1 \mathrm{~h}$. Mutations in $P D X 1$ genes affect pyridoxine (vitamin B6) biosynthesis, however, the role of PDX1.2 has not been clarified yet [46]. Vitamin B6 is known to play a protective role against oxidative stress and it is a cofactor in many biochemical processes $[46,47]$. Thus, vitamin B6 may be an important component in the response of seeds to high temperature.

\section{Discussion}

Seed germination is controlled by endogenous factors, such as the degree of dormancy, as well as environmental cues, including light, temperature and water. In Arabidopsis, germination of WT seeds is delayed or moderately inhibited at temperatures between 28 and $32^{\circ} \mathrm{C}$, but completely inhibited at $34^{\circ} \mathrm{C}[39,48]$. Physiological, genetic and molecular studies have highlighted the important and opposite roles of ABA and GA in promoting and alleviating thermoinhibition of seed germination, respectively $[39,48-52]$. The master regulator of seed maturation, FUS3, controls the ABA/GA ratio by negatively regulating GA biosynthesis, while positively regulating ABA levels [16,17]. Here, we show that one of the functions of FUS3 during post-embryonic development is to regulate seed responses to high temperatures, by delaying seed germination and inhibiting seedling growth partly through the regulation of ABA biosynthesis (Figure 7; see also below).

High temperature induces de novo FUS3 mRNA synthesis and FUS3 protein accumulation during imbibition

FUS3 plays a predominant role during mid-late embryogenesis by promoting seed dormancy and maturation, while inhibiting precocious germination of immature seeds [10]. Accordingly, FUS3 mRNA level is high during mid-late embryogenesis and dramatically decreases during germination and throughout vegetative growth $[19,32]$. Furthermore, the level of the FUS3 protein does 
Table 1 Core HSR genes.

\begin{tabular}{|c|c|}
\hline \multicolumn{2}{|c|}{ A) Core HSR genes upregulated at 1, 12 and $24 \mathrm{~h}$} \\
\hline AGI & Annotation \\
\hline At3g29810 & COBRA-like protein 2 precursor (COBL2) \\
\hline At5g56600 & profilin 3 (PFN3_PRF3) \\
\hline At5g48570 & FKBP-type peptidyl-prolyl cis-trans isomerase (FKBP65_ROF2) \\
\hline At5g48480 & Lactoylglutathione lyase/glyoxalase I \\
\hline At5g37670 & HSP20-like chaperones \\
\hline At5g12110 & Glutathione S-transferase, C-terminal-like; Translation elongation factor EF1B/ribosomal protein S6 \\
\hline At5g09590 & mitochondrial HSO70 2 (HSC70-5_MTHSC70-2) \\
\hline At4g29770 & Target of trans acting-siR480/255 \\
\hline At4g23570 & SGT1A_phosphatase-related \\
\hline At4g02980 & endoplasmic reticulum auxin binding protein 1 (ABP1) \\
\hline At4g10250 & ATHSP22.0_HSP20-like chaperones \\
\hline At1g66080 & unknown protein \\
\hline At3g14880 & unknown protein \\
\hline At3g24500 & multiprotein bridging factor 1 C (ATMBF1C) \\
\hline At3g 16050 & pyridoxine biosynthesis 1.2 (A37_ATPDX1.2) \\
\hline At3g07150 & unknown protein \\
\hline At1g07350 & RNA-binding protein (RRM/RBD/RNP motifs) \\
\hline At1g26800 & RING/U-box superfamily protein \\
\hline At1g35660 & unknown protein \\
\hline At2g25140 & casein lytic proteinase B4 (CLPB-M_CLPB4_HSP98.7) \\
\hline At2g26150 & heat shock transcription factor A2 (ATHSFA2) \\
\hline \multicolumn{2}{|c|}{ B) Core HSR genes downregulated at 1, 12 and $24 \mathrm{~h}$} \\
\hline$\overline{\mathrm{AGI}}$ & Annotation \\
\hline At5g51190 & Integrase-type DNA-binding \\
\hline At3g48140 & B12D protein \\
\hline At3g08730 & protein-serine kinase 1 (ATPK1_ATPK6_ATS6K1) \\
\hline At1g28110 & serine carboxypeptidase-like 45 (SCPL45) \\
\hline
\end{tabular}

List of $H S R$ genes whose expression level is increased or decreased in seeds imbibed at $32^{\circ} \mathrm{C}$ at all time points (1, 12 and $\left.24 \mathrm{~h}\right)$. Genes were filtered as described in the methods

not correlate with that of its mRNA and remains undetected after mid-embryogenesis $[17,19]$. Given the very low level of FUS3 expression post-embryonically, one question raised by these studies is the physiological role of FUS3 during post-embryonic development. Here we found that seeds imbibed at $32^{\circ} \mathrm{C}$ rapidly degrade FUS3 mRNA stored in the seed and induce de novo FUS3 mRNA synthesis at $12 \mathrm{~h}$, which is then followed by the accumulation of the FUS3 protein by $48 \mathrm{~h}$ (Figure 2). Notably, the FUS3 mRNA levels at $32^{\circ} \mathrm{C}$ are $\sim 15$ to 70 fold lower than those measured $1 \mathrm{~h}$ after imbibition at $21^{\circ} \mathrm{C}$. Despite the lower mRNA level, the FUS3 protein is detected in seeds imbibed at $32^{\circ} \mathrm{C}$ but not at $21^{\circ} \mathrm{C}$. We have previously shown that FUS3 is a short-lived protein and posttranslational regulation is one of the mechanisms that maintains FUS3 protein levels very low (undetectable) after mid-embryogenesis and during germination [19]. Therefore, it is likely that the accumulation of the FUS3-GFP protein at $32^{\circ} \mathrm{C}$ is due to translational and/or posttranslational regulation induced by HS.

Considering the FUS3-GFP protein is not detected in FUS3:FUS3-GFP seeds imbibed on ABA at $21^{\circ} \mathrm{C}$ (Additional file 1), $A B A$ alone does not seem to be sufficient to induce FUS3-GFP protein accumulation during imbibition at high temperature. However, ABA may be required to maintain FUS3 protein levels high by a positive feedback regulation, as ABA was previously shown to positively regulate FUS3 abundance in ML1:FUS3GFP seedlings (Figure 7) [17]. Interestingly, we found that at $32^{\circ} \mathrm{C}$ the FUS3 protein can only be detected in seeds that have commenced germination (radicle protrusion from the seed coat) and is not detected in inhibited seeds (no radicle emergence) or in seedlings that have fully emerged from the seed coat. This indicates that FUS3 is only active in a small developmental window 


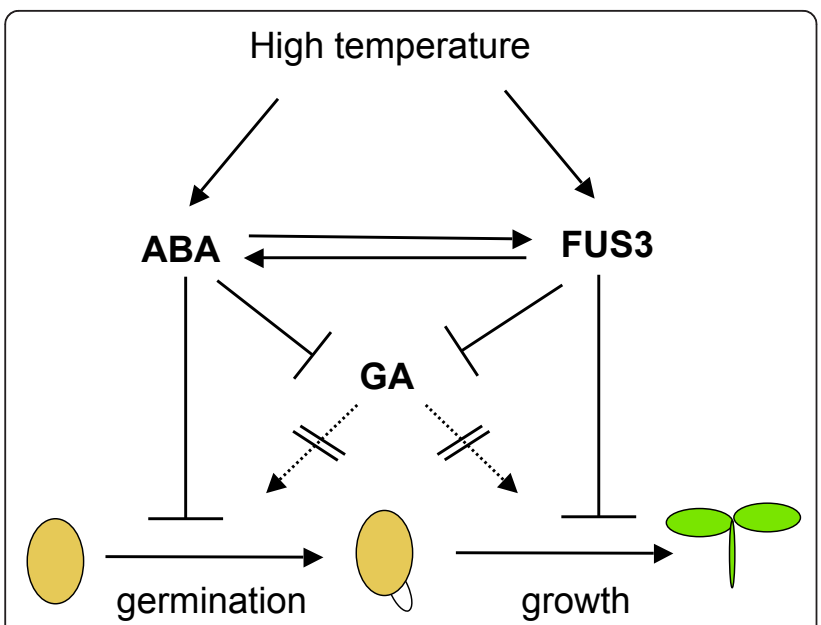

Figure 7 Proposed model of thermoinhibition of seed germination. During seed germination at supraoptimal temperature, induction of $A B A$ and repression of GA syntheses and signaling delays germination. FUS3 acts in a short developmental window to prevent seedling growth, by positively regulating $A B A$ while negatively regulating GA biosyntheses. ABA increases FUS3 stability by positive feedback regulation.

during germination at high temperature and may be important to delay germination and inhibit seedling growth (Figure 7; see also below).

\section{Overexpression of FUS3 inhibits seed germination at supraoptimal temperature partly through positive regulation of $A B A$ biosynthesis}

Overexpression of FUS3 has a protective role for the embryo during germination at high temperature. Indeed, at $32^{\circ} \mathrm{C}$ WT seeds show delayed germination compared to the optimal temperature of $21^{\circ} \mathrm{C}$ and suffer from heat-stress related damages. In contrast, seeds overexpressing FUS3 post-embryonically (ML1:FUS3-GFP) show a strong thermoinhibition and result in a much higher seedlings survival than WT when shifted at $21^{\circ} \mathrm{C}$ (Figure 3). Thermoinhibition exhibited by ML1:FUS3GFP seeds at $32^{\circ} \mathrm{C}$ can be alleviated by the ABA biosynthesis inhibitor, fluridone, suggesting it is dependent on de novo ABA biosynthesis. Furthermore, ML1:FUS3GFP seeds are more dormant than WT at $21^{\circ} \mathrm{C}$ and the delayed germination exhibited by ML1:FUS3-GFP seeds at optimal temperature can also be rescued by fluridone. Considering that transient activation of FUS3 postembryonically increases ABA levels and that ML1:FUS3GFP seeds are hypersensitive to ABA even at the optimal temperature of $21^{\circ} \mathrm{C}$ [17], we conclude that seeds overexpressing FUS3 are hypersensitive to high temperature and induces thermoinhibition through de novo activation of $A B A$ biosynthesis. These findings mirror previous findings showing that thermoinhibition of germination at $34^{\circ} \mathrm{C}$ is partly due to de novo $\mathrm{ABA}$ biosynthesis and that loss-of-function mutants affected in ABA biosynthesis show resistance to thermoinhibition [39]. Thus, increased seed dormancy and/or ABA biosynthesis is advantageous as it delays or prevents germination at high temperatures and protects the developing seedling from temperature-induced damage.

Immature green seeds of the fus3-3 loss-of-function mutant, which accumulate less ABA during embryogenesis, are less dormant than WT at $21^{\circ} \mathrm{C}$ (Figure 3) $[10,16,17]$. Accordingly, fus $3-3$ is more resistant than WT to thermoinhibition at $32^{\circ} \mathrm{C}$. Surprisingly, thermoinhibition of WT immature green seeds is not dependent on ABA biosynthesis, as it cannot be rescued by fluridone. Thus, it appears that different mechanisms may regulate immature and mature seed germination at supraoptimal temperature. In the future, the sensitivity of different stages of immature seeds should be assessed in order to determine the role of $\mathrm{ABA}$ in thermoinhibition of immature seeds. Indeed, two peaks of ABA occur during seed development in Arabidopsis and many species; the first maternally-derived ABA peak is required to prevent precocious germination while the second ABA peak is made by the embryo and important to induce and maintain dormancy $[2,3]$. Thus, the response of immature seeds to fluridone may be dependent on the stage of development.

\section{Transcriptomic analysis of WT seeds imbibed at supraoptimal temperature}

A transcriptomic analysis of seeds imbibed at $32^{\circ} \mathrm{C}$ shows differential expression of several genes involved in ABA and GA metabolisms as well as signaling. Among the ABA biosynthetic genes, NCED1, NCED5, NCED9, $A B A 1$ and $A B A 2$ showed increased expression at 12 and/or $24 \mathrm{~h}$, while CYP707A2, the most abundant ABA catabolic gene during germination [39], showed a transient reduction of expression at $12 \mathrm{~h}$. These changes in gene expression are consistent with previous quantifications of transcript levels of several ABA metabolic genes during imbibition at $34^{\circ} \mathrm{C}$ [39]. The increase in FUS3 mRNA level at 12 and $24 \mathrm{~h}$ parallels that of the ABA biosynthetic genes. Interestingly, all ABA metabolic genes identified in this microarray with the exception of NCED1 contain RY elements, which interact with B3-domain proteins [24-26]. Since FUS3 positively regulates $A B A$ levels, these genes may be directly regulated by FUS3 and/or other B3 domain proteins.

Genetic analysis indicates that ABA biosynthesis and signaling are required for thermoinhibition of germination and also for the acquisition of thermotolerance during vegetative growth $[39,48,53]$. Differences were observed in the degree of responses to high temperature of single or higher order ABA biosynthetic mutants, with $a b a 1$ and the triple nced 2 nced 5 nced 9 mutants 
being strongly resistant to thermoinhibition $[39,48]$. In agreement, ABA1, NCED5 and NCED9 show the highest increase in transcript level in our microarray (Figure 6).

$A B A$ insensitive (abi) mutants affected in ABA signaling display different sensitivities to high temperature; for example, abi1 is strongly resistant to thermoinhibition, while abi3 is moderately resistant and abi2, abi4 and abi5 are sensitive to thermoinhibition [48]. Several ABA signaling components show altered expression during imbibition at high temperature (Figure 6), including several members of the ABA receptor family (PYLs/RCARs) and downstream signaling and response genes (PP2C phosphatases, SnRK kinases and transcription factors) $[44,54,55]$. The regulation and function of most of these genes during germination at high temperature has not been tested. Together with the fact that not all ABA signaling mutants tested so far are resistant to thermoinhibition, this suggests that different components of the ABA pathway are used to delay or inhibit seed germination at high temperatures.

Our transcriptomic analysis shows that the expression levels of several GA biosynthetic genes were reduced in response to high temperature. Interestingly, GA3ox1, GA3ox2 and GA20ox1, which show the strongest and prolonged reduction in mRNA levels, are under FUS3mediated repression $[17,18]$. Genetic and chemical studies have shown that thermoinhibition of seed germination in Arabidopsis requires the suppression of GA biosynthesis and signaling [39]. Indeed, thermoinhibition can be partly alleviated by the addition of exogenous GA. Furthermore, loss-of-function mutations in some negative regulators of GA signaling (spy and $r g l 2$ ) confer resistance to thermoinhibition, while mutations in several others ( $r g l 1, r g l 3, r g a$ and gai) do not [39]. Analysis of multiple combinations of DELLA mutants may be required to fully understand the role of GA signaling components in thermoinhibition. Interestingly, our transcriptomic analysis shows that repression of GA signaling at high temperature starts with the transient downregulation of SLY1 at $12 \mathrm{~h}$ and is followed by the upregulation of GID1A and SPY at $24 \mathrm{~h}$ (Figure 6). Thus, downregulating $S L Y 1$, which encodes an F-box protein involved in the degradation of multiple DELLA proteins [56,57], may be sufficient to dampen GA signaling during germination at high temperature. The induction at $24 \mathrm{~h}$ of GID1A, coding for the most abundant GA receptor in dry and imbibed seeds, is possibly due to a feedback regulation triggered by changes in the ABA/GA ratio, as previously suggested [58]. The increase in GID1A level at 24 h may also counteract the effect of decreased SLY1 mRNA at this time point, since GID1 overexpression down-regulates DELLA repression [59]. Genetic analysis of sly and gid mutants is needed to dissect the role of GA in thermoinhibition of germination.
Seed-specific and seed-maturation related genes are induced by high temperature at 12 and $24 \mathrm{~h}$. A large number of these genes, which are among the highest expressed in dry seeds [30], also show the highest abundance of transcripts in seeds imbibed at $32^{\circ} \mathrm{C}$ (Additional files $2,3,4)$. A survey of public microarrays shows that most of the SSP/LEA genes displaying highest mRNA levels during seed imbibition at $32^{\circ} \mathrm{C}$ are preferentially expressed during seed development [60]. Furthermore, most of the SSP/LEA genes showing increased expression at $32^{\circ} \mathrm{C}$, also show induction by ABA in seeds or seedlings [60]. This suggests that at high temperature, the expression levels of SSP/LEA genes may fluctuate in response to changes in ABA level. This also corroborates the view that SSP/LEA genes are strongly regulated by ABA, but play different roles beyond seed maturation [41]. Among the known global regulators of late embryogenesis, FUS3 is the only gene induced by HS in our microarray, and thus may play a predominant role in the regulation of seed-specific programs during germination at high temperature (Additional files 2, 3, 4). This was surprising, as abi3 mutants have been recovered in genetic screens for high-temperature resistant mutants [48]. The reduced sensitivity of abi3 to high temperature during germination is likely a consequence of the inability of this mutant to respond to ABA. Possibly, high temperature may affect translational and/or posttranslational regulation of $\mathrm{ABI} 3$ and/or other components required to act in concert with $\mathrm{ABI} 3$, such as ABI5, without affecting $A B I 3$ transcription directly [61]. Although $A B I 4$ and 5 expression levels is altered at $32^{\circ} \mathrm{C}$, abi5 and also abi4 mutants have WT responses in thermoinhibition of seed germination [48]. Several uncharacterized bZIP genes change in expression level at 12 and/or $24 \mathrm{~h}$ after heat stress and may play more predominant roles than $A B I 4$ and $A B I 5$ during germination at high temperatures (Additional file 3, Additional file 4).

Several stress-related genes are induced by high temperature in our microarrays, including HSF, HSP as well as $L E A$ genes, most of which are abundant during seed maturation and are also thought to play a role in several abiotic stress responses [41,62]. Among the HS-related genes, HSFA9 expression in vitro has been shown to be induced by ABI3, but not FUS3. Furthermore, HSFA9 mRNA is $\sim 10$-fold higher in seeds imbibed on ABA, suggesting a preferential regulation of HSFA9 by ABA and ABI3 [31,60]. Although $A B I 3$ transcripts do not increase in seeds imbibed at high temperature, activation of the HSFA9 promoter during HS may require additional factors beside ABI3. Seed imbibition at high temperature induces the expression of several HSFs at different times, some of which (HSFA2) play important roles during the acquisition of thermotolerance in 
seedlings, while others (HSFA4 and HSFC1) have not been previously shown to be regulated by HS. This is possibly due to the long HS exposure time (12 and 24 h) and stage of development (seed imbibition) used in this microarray compared to previous ones [43,63-65]. The role of these HSF in thermoinhibition and during prolonged HS remains to be elucidated.

\section{Conclusion}

In this study, we have uncovered a novel function for the master regulator of seed maturation, FUS3, in delaying germination and inhibiting seedling growth at supraoptimal temperature. FUS3 mRNA and protein levels are induced de novo when seeds are imbibed at supraoptimal temperature. Furthermore, hyperdormant ML1:FUS3-GFP seeds are hypersensitive to thermoinhibition, and this is partly dependent on de novo ABA synthesis. Physiologically, this is important since increased dormancy can delay or prevent germination at high temperatures and thus has a protective role for the embryo. Transcriptomic analysis of seeds imbibed at high temperature reveals that a complex program is activated, which involves not only the regulation of heat and dehydration response genes to adjust cellular functions, but also the induction of $\mathrm{ABA}$ and repression of GA metabolism and response genes. Finally, our study shows that seeds imbibed at high temperature also activate the expression of genes involved in seed-maturation programs, and that FUS3 is the only master regulator of late embryonic development activated during imbibition at supraoptimal temperature. Considering FUS3 is induced by heat stress, regulated by ABA/GA levels and itself regulates $\mathrm{ABA} / \mathrm{GA}$ levels and seed maturation programs, this gene may play an important role in seed responses to high temperature.

We propose a model where FUS3 protein and ABA levels increase during seed imbibition at supraoptimal temperature to delay or inhibit germination through shared as well as independent pathways (Figure 7). Once induced by HS, FUS3 may functions to delay seed germination and prevent seedling growth under unfavorable conditions through positive regulation of $A B A$ synthesis. ABA in turn stabilizes FUS3 levels establishing a positive feedback regulation. FUS3 and ABA negatively regulate GA biosynthesis to delay or prevent germination at supraoptimal temperature.

\section{Methods}

Plant material, growth conditions and seed germination For germination assays, 50-100 Arabidopsis WT (Columbia ecotype) or ML1:FUS3-GFP (MFG; [17]) overexpressing dry seeds were sterilized and imbibed on filter paper placed on MS plates for the indicated times. The loss-of-function fus3-3 seeds [10] were processed in the same way, but they were harvested from immature (green/yellow) siliques because of their desiccation intolerance phenotype [10]. All germination assays were conducted in triplicates. Seeds were germinated under constant light in controlled seed incubators at 21 or $32^{\circ}$ C. For the recovery period, filter papers were transferred to a fresh MS plate at $21^{\circ} \mathrm{C}$ for 6 days. Germination rates were scored based on radicle protrusion. Two independent experiments were conducted and a typical result is shown.

\section{Confocal microscopy}

Imbibed FUS3:GFP [19] and FUS3:FUS3-GFP (FFG)[17] embryos were dissected from the seed coats, mounted on slides in water and imaged by confocal microscopy as previously described [19]. The same confocal settings were used to detect GFP fluorescence intensities at 21 and $32^{\circ} \mathrm{C}$.

\section{Immunoblots}

Isolation of proteins and immunoblots were performed as described [19]. GFP and FUS3-GFP were detected with a rabbit anti-GFP (1:3000) polyclonal antibody (Abcam) and Donkey anti-rabbit conjugated to Horse Radish Peroxidase (HRP) (1:10000) antibody (Cederlane).

Microarray analysis and quantitative real time PCR (qPCR) Seeds were sterilized and imbibed on filter paper placed on MS plates for the indicated times. Seeds were germinated under constant light in controlled seed incubators at 21 or $32^{\circ} \mathrm{C}$ and samples were collected after 1,12 and $24 \mathrm{~h}$. Total RNA extraction and qPCR was done as previously described using primers listed in Additional file 11[19]. The mean value of three replicates was normalized using ACTIN7 or UBC28 as the internal control. Results are plotted as the ratio to the lowest detected level. Two independent experiments were conducted with similar results and one is shown. RNA was used for cDNA synthesis, labeling, and hybridization of Affymetrix ATH1 arrays according to the Affymetrix GeneChip Expression Analysis technical manual (http://www. affymetrix.com) by the CAGEF Affymetrix GeneChip Facility (Cell \& Systems Biology, University of Toronto). Duplicate biological replicates were hybridized to separate arrays. Data file quantification and normalization were performed using the GCOS/MAS5 algorithm with a TGT value of 100 . Data quality was confirmed through the use of internal controls and by comparing replicates. Data were then analyzed using a combination of tools including the Eisen lab's Cluster and TreeView programs [66], the Bio-Array Resource at the University of Toronto [67], with BioConductor/R [68] and with Microsoft Excel. An average expression value for each 
gene for each experimental condition was generated from the normalized data from the duplicate arrays. Genes were labeled as present only if the probability of detection was $P<0.05$. Data were validated by comparison with real-time PCR for a representative set of genes (Additional file 12). Data were further filtered such that genes were excluded if there was less than a 1.8-fold change $\left(\log _{2} 0.85\right)$. Genes that passed this filtering were analyzed further. Promoter element analysis was performed on 1,000 bp of upstream gene sequences using Promomer (http://bar.utoronto.ca; [67]) and Motif Analisis from TAIR (http://www.arabidopsis.org/tools/bulk/ motiffinder/index.jsp). The AgriGO web-based tool (http://bioinfo.cau.edu.cn/agriGO) was used for the Gene Ontology (GO) enrichment analysis [40]. Further expression analysis of selected gene groups was conducted using eNorthern (http://bar.utoronto.ca) [67]. Cluster analysis was done using the Eisen lab's Cluster program [66] on the fold-change data set over three time points. Self-organizing maps were first generated across the genes, and the membership of the maps was used to instruct the gene cluster order during hierarchical clustering using the Pearson (centered) correlation coefficient and average linkage. TreeView was used to visualize the resulting clustergram and data matrix.

\section{Additional material}

Additional file 1: FUS3-GFP protein expression in FUS3:FUS3-GFP seeds during imbibition at $32^{\circ} \mathrm{C}$, and in the presence or absence of ABA or paclobutrazol at $21^{\circ} \mathrm{C}$. (A, B) Confocal images showing FUS3GFP fluorescence in the epidermis of FUS3:FUS3-GFP embryos. Seeds were imbibed on MS media with or without hormones or inhibitors for $72 \mathrm{~h}$. During germination on MS media, the FUS3-GFP fluorescence is detected at $32^{\circ} \mathrm{C}$ (left two panels; red bar), but not at $21^{\circ} \mathrm{C}$ (black bar) by confocal microscopy. Treatments with either ABA $(0.4,0.8,1.2 \mu \mathrm{M})$ or paclobutrazol (PAC; $0.4 \mu \mathrm{M})$ at $21{ }^{\circ} \mathrm{C}$ are not sufficient to induce FUS3GFP fluorescence at $72 \mathrm{~h}$ after imbibition (HAl). Similar results were obtained at $48 \mathrm{HAl}$ (data not shown). Duplicate experiments were conducted and one is shown. Comparable confocal settings were used in all images. A) Green channel, GFP; B) Merge image of green channel (GFP) and red channel (propidium iodide).

Additional file 2: List of upregulated and downregulated genes at 1 h. List of upregulated (tab 1) and downregulated (tab 2) HSR genes in seeds imbibed at $32^{\circ} \mathrm{C}$ for $1 \mathrm{~h}$ compared to the $21^{\circ} \mathrm{C}$ control, and top highest expressed or repressed genes at $1 \mathrm{~h}$ (tab 3). Genes were filtered as described in the methods.

Additional file 3: List of upregulated and downregulated genes at $12 \mathbf{~ h}$. List of upregulated (tab 1) and downregulated (tab 2) HSR genes in seeds imbibed at $32^{\circ} \mathrm{C}$ for $12 \mathrm{~h}$ compared to the $21^{\circ} \mathrm{C}$ control, and top highest expressed or repressed genes at $12 \mathrm{~h}$ (tab 3). Genes were filtered as described in the methods.

Additional file 4: List of upregulated and downregulated genes at $24 \mathbf{~ h}$. List of upregulated (tab 1) and downregulated (tab 2) HSR genes in seeds imbibed at $32^{\circ} \mathrm{C}$ for $24 \mathrm{~h}$ compared to the $21^{\circ} \mathrm{C}$ control, and top highest expressed or repressed genes at $24 \mathrm{~h}$ (tab 3). Genes were filtered as described in the methods.

Additional file 5: Summary of GO-terms enrichments in upregulated and downregulated genes. GO-terms enrichments in upregulated and downregulated genes at each time point using agriGO [40]. The $\mathrm{Y}$-axis is the percentage of genes mapped by the term, and represents the abundance of the GO term. The percentage for each time point is calculated by the number of genes mapped to the $\mathrm{GO}$ term divided by the number of all genes in each time point (blue columns). The same calculation was applied to a default reference list (green columns). The $\mathrm{X}$-axis is the $\mathrm{GO}$ terms definition. A detailed representation of the subbiological functions within the GO-term categories can be seen in Additional files 6-10.

Additional file 6: GO-terms enrichments in upregulated genes at 1 h. Hierarchical tree graph of overrepresented GO terms in biological process categories generated by SEA using AgriGO [40]. Boxes in the graph represent GO terms labeled by their GO ID, term definition and statistical information. The significant term (adjusted $P \geq 0.05$ ) are marked with color, while non-significant terms are shown as white boxes. In the diagram, the degree of color saturation of a box is positively correlated to the enrichment level of the term (going from yellow, $P=0.05$ to red, $P=5 \mathrm{e}-10)$. Solid, dashed, and dotted lines represent two, one and zero enriched terms at both ends connected by the line, respectively.

Additional file 7: GO-terms enrichments in upregulated genes at 12 h.

Additional file 8: GO-terms enrichments in downregulated genes at $12 \mathrm{~h}$.

Additional file 9: GO-terms enrichments in upregulated genes at 24 h.

Additional file 10: GO-terms enrichments in downregulated genes at $24 \mathrm{~h}$.

Additional file 11: Primers used for qPCR. Sequences of primers used in $\mathrm{QPCR}$ reactions.

Additional file 12: qPCR validation of selected genes differentially regulated in the microarray. A) Relative expression levels of select HSR genes measured by qPCR. ACTIN7 was used as the internal control. The mean value of three replicates was normalized using ACTIN 7 as the internal control. Results are plotted as the ratio to the lowest detected level. Two independent experiments were conducted with similar results and one is shown. B) Fold change $\left(\log _{2}\right)$ expression at $32^{\circ} \mathrm{C}$ versus $21^{\circ} \mathrm{C}$ of genes shown in $\mathrm{A}$.

\section{Acknowledgements}

We are grateful to K. Breitkreuz for critical reading of the manuscript. This work was supported by NSERC and Connaught New Staff Matching funds to S.G., NSERC to N.J.P. and CAGEF to H.N.

\section{Author details}

'Department of Biological Sciences, University of Toronto, 1265 Military Trail, Toronto, ON, M1C 1A4 Canada. ${ }^{2}$ Department of Cell and Systems Biology, University of Toronto, 25 Harbord Street, Toronto, ON, M5S 3G5 Canada. ${ }^{3}$ Centre for the Analysis of Genome Evolution and Function (CAGEF), University of Toronto, 25 Harbord Street, Toronto, ON, M5S 3G5 Canada.

\section{Authors' contributions}

SG designed the assays, supervised RSC and funded this study. SG and SRC wrote the manuscript and prepared the figures. RSC performed all the biological experiments, including germination assays, RNA and protein extractions, CDNA synthesis and GRT-PCR, western blot, confocal microscopy (Figures 1,2,3,5,6). HN and NP performed microarray data quality, statistical and cluster analyses (Figure 4, Additional files 2, 3, 4). All authors read and confirmed the manuscript.

Received: 19 September 2011 Accepted: 27 January 2012 Published: 27 January 2012

\section{References}

1. Bewley JD: Seed germination and dormancy. Plant Cell 1997, 9:1055-1066.

2. Finkelstein RR, Gampala SSL, Rock CD: Abscisic acid signaling in seeds and seedlings. Plant Cell 2002, 14:S15-S45. 
3. Finkelstein R, Reeves W, Ariizumi T, Steber C: Molecular aspects of seed dormancy. Annu Rev Plant Biol 2008, 59:387-415.

4. Suzuki M, McCarty DR: Functional symmetry of the B3 network controlling seed development. Curr Opin Plant Biol 2008, 11:548-53.

5. Koornneef M, Reuling G, Karssen CM: The isolation and characterization of abscisic acid-insensitive mutants of Arabidopsis thaliana. Physiol Plant 1984, 61:377-383.

6. Nambara E, Naito S, McCourt P: A mutant of Arabidopsis which is defective in seed development and storage protein accumulation is a new abi allele. Plant J 1992, 2:435-441.

7. Nambara $E$, Keith $K$, McCourt $P$, Naito S: Isolation of an internal deletion mutant of the Arabidopsis thaliana ABI3 gene. Plant Cell Physiol 1994, 3:509-513.

8. Meinke DW, Franzmann LH, Nickle TC, Yeung EC: Leafy cotyledon mutants of Arabidopsis. Plant Cell 1994, 6:1049-1064.

9. West M, Yee KM, Danao J, Zimmerman JL, Fischer RL, Goldberg RB, Harada JJ: LEAFY COTYLEDON1 is an essential regulator of late embryogenesis and cotyledon identity in Arabidopsis. Plant Cell 1994, 6:1731-1745

10. Keith $K$, Krami M, Dengler NG, McCourt P: fusca3: a heterochronic mutation affecting late embryo development in Arabidopsis. Plant Cell 1994, 6:589-600.

11. Parcy F, Valon C, Raynal M, Gaubier-Comella P, Delseny M, Giraudat J: Regulation of gene expression programs during Arabidopsis seed development: roles of the ABI3 locus and of endogenous abscisic acid. Plant Cell 1994, 6:1567-1582.

12. Raz V, Bergervoet JH, Koornneef M: Sequential steps for developmental arrest in Arabidopsis seeds. Development 2001, 128:243-252.

13. Kroj T, Savino G, Valon C, Giraudat J, Parcy F: Regulation of storage protein gene expression in Arabidopsis. Development 2003, 130:6065-6073.

14. To A, Valon C, Savino G, Guilleminot J, Devic M, Giraudat J, Parcy F: A network of local and redundant gene regulation governs Arabidopsis seed maturation. Plant Cell 2006, 18:1642-1651.

15. Nambara E, Marion-Poll A: ABA action and interactions in seeds. Trends Plant Sci 2003, 8:213-217.

16. Nambara E, Hayama R, Tsuchiya $Y$, Nishimura M, Kawaide H, Kamiya $Y$, Naito S: The role of ABI3 and FUS3 loci in Arabidopsis thaliana on phase transition from late embryo development to germination. Dev Biol 2000, 220:412-423.

17. Gazzarrini S, Tsuchiya Y, Lumba S, Okamoto M, McCourt P: The transcription factor FUSCA3 controls developmental timing in Arabidopsis through the hormones gibberellin and abscisic acid. Dev Cell 2004, 7:373-385

18. Curaba J, Moritz T, Blervaque R, Parcy F, Raz V, Herzog M, Vachon G: AtGA3ox2, a key gene responsible for bioactive gibberellin biosynthesis, is regulated during embryogenesis by LEAFY COTYLEDON2 and FUSCA3 in Arabidopsis. Plant Physiol 2004, 136:3660-3669.

19. Lu QS, dela Paz J, Pathmanathan A, Chiu RS, Tsai AY, Gazzarrini S: The Cterminal domain of FUSCA3 negatively regulates MRNA and protein levels and mediates sensitivity to the hormones abscisic acid and gibberellic acid in Arabidopsis. Plant J 2010, 64:100-113.

20. Giraudat J, Hauge BM, Valon C, Smalle J, Parcy F, Goodman HM: Isolation of the Arabidopsis ABI3 gene by positional cloning. Plant Cell 1992, 4:1251-1261.

21. Brady SM, Sarkar SF, Bonetta D, McCourt P: The ABSCISIC ACID INSENSITIVE 3 (ABI3) gene is modulated by farnesylation and is involved in auxin signaling and lateral root development in Arabidopsis. Plant $J$ 2003, 34:67-75

22. Stone SL, Braybrook SA, Paula SL, Kwong LW, Meuser J, Pelletier J, Hsieh TF, Fischer RL, Goldberg RB, Harada JJ: Arabidopsis LEAFY COTYLEDON2 induces maturation traits and auxin activity: implications for somatic embryogenesis. Proc Natl Acad Sci USA 2008, 105:3151-3156.

23. Yamamoto A, Kagaya Y, Usui H, Hobo T, Takeda S, Hattori T: Diverse roles and mechanisms of gene regulation by the Arabidopsis seed maturation master regulator FUS3 revealed by microarray analysis. Plant Cell Physiol 2010, 51:2031-2046.

24. Reidt W, Wohlfarth T, Ellerström M, Czihal A, Tewes A, Ezcurra I, Rask L, Bäumlein $\mathrm{H}$ : Gene regulation during late embryogenesis: the RY motif of maturation-specific gene promoters is a direct target of the FUS3 gene product. Plant J 2000, 21:401-408.
25. Mönke G, Altschmied L, Tewes A, Reidt W, Mock HP, Baumlein H, Conrad U: Seed-specific transcription factors ABI3 and FUS3: molecular interaction with DNA. Planta 2004, 219:158-166.

26. Braybrook SA, Stone SL, Park S, Bui AQ, Le BH, Fischer RL, Goldberg RB, Harada JJ: Genes directly regulated by LEAFY COTYLEDON2 provide insight into the control of embryo maturation and somatic embryogenesis. Proc Natl Acad Sci USA 2006, 103:3468-3473.

27. Busk PK, Pagès M: Regulation of abscisic acid-induced transcription. Plant Mol Biol 1998, 37:425-435.

28. Ezcurra I, Ellerström M, Wycliffe $P$, Stålberg $K$, Rask L: Interaction between composite elements in the napA promoter: both the B-box ABAresponsive complex and the RY/G complex are necessary for seedspecific expression. Plant Mol Biol 1999, 40:699-709.

29. Vasil V, Marcotte WR Jr, Rosenkrans L, Cocciolone SM, Vasil IK, Quatrano RS, McCarty DR: Overlap of Viviparous1 (VP1) and abscisic acid response elements in the Em promoter: G-box elements are sufficient but not necessary for VP1 transactivation. Plant Cell 1995, 9:1511-1518.

30. Nakabayashi K, Okamoto M, Koshiba T, Kamiya Y, Nambara E: Genomewide profiling of stored mRNA in Arabidopsis thaliana seed germination: epigenetic and genetic regulation of transcription in seed. Plant J 2005, 41:697-709.

31. Kotak S, Vierling E, Bäumlein H, von Koskull-Döring P: A novel transcriptional cascade regulating expression of heat stress proteins during seed development of Arabidopsis. Plant Cell 2007, 19:182-195.

32. Luerssen H, Kirik V, Herrmann P, Misera S: FUSCA3 encodes a protein with a conserved VP1/ABI3-like B3 domain which is of functional importance for the regulation of seed maturation in Arabidopsis thaliana. Plant $J$ $1998,15: 755-764$

33. Lotan T, Ohto M, Yee KM, West MA, Lo R, Kwong RW, Yamagishi K, Fischer RL, Goldberg RB, Harada JJ: Arabidopsis LEAFY COTYLEDON1 is sufficient to induce embryo development in vegetative cells. Cell 1998, 93:1195-1205.

34. Tsuchiya Y, Nambara E, Naito S, McCourt P: The FUS3 transcription factor functions through the epidermal regulator TGG1 during embryogenesis in Arabidopsis. Plant J 2004, 37:73-81.

35. Stone SL, Kwong LW, Yee KM, Pelletier J, Lepiniec L, Fischer RL, Goldberg RB, Harada JJ: LEAFY COTYLEDON2 encodes a B3 domain transcription factor that induces embryo development. Proc Natl Acad Sci USA 2001, 20:11806-11811.

36. Kagaya Y, Toyoshima R, Okuda R, Usui H, Yamamoto A, Hattori T: LEAFY COTYLEDON1 controls seed storage protein genes through its regulation of FUSCA3 and ABSCISIC ACID INSENSITIVE3. Plant Cell Physiol 2005, 46:399-406.

37. Kagaya Y, Okuda R, Ban A, Toyoshima R, Tsutsumida K, Usui H, Yamamoto A, Hattori T: Indirect ABA-dependent regulation of seed storage protein genes by FUSCA3 transcription factor in Arabidopsis. Plant Cell Physiol 2005, 46:300-311.

38. Kim JY, Kwak KJ, Jung HJ, Lee HJ, Kang H: MicroRNA402 affects seed germination of Arabidopsis thaliana under stress conditions via targeting DEMETER-LIKE Protein3 mRNA. Plant Cell Physiol 2010, 51:1079-1083.

39. Toh S, Imamura A, Watanabe A, Nakabayashi K, Okamoto M, Jikumaru $Y$, Hanada A, Aso Y, Ishiyama K, Tamura N, luchi S, Kobayashi M, Yamaguchi S, Kamiya Y, Nambara E, Kawakami N: High temperature-induced abscisic acid biosynthesis and its role in the inhibition of gibberellin action in Arabidopsis seeds. Plant Physiol 2008, 146:1368-1385.

40. Zhou Du, Zhou X, Ling Y, Zhang Z, Zhen Su: agriGO: a GO analysis toolkit for the agricultural community. Nucl Acids Res 2010, 38:W64-W70.

41. Hirayama T, Shinozaki K: Research on plant abiotic stress responses in the post-genome era: past, present and future. Plant J 2010, 6:1041-1052.

42. Charng YY, Liu HC, Liu NY, Chi WT, Wang CN, Chang SH, Wang TT: A heatinducible transcription factor, $\mathrm{HsfA2}$, is required for extension of acquired thermotolerance in Arabidopsis. Plant Physiol 2007, 143:251-262.

43. Larkindale J, Vierling E: Core genome responses involved in acclimation to high temperature. Plant Physiol 2008, 146:748-761.

44. Cutler SR, Rodriguez PL, Finkelstein RR, Abrams SR: Abscisic acid: emergence of a core signaling network. Annu Rev Plant Biol 2010, 61:651-679.

45. Sakuma Y, Maruyama K, Qin F, Osakabe Y, Shinozaki K, YamaguchiShinozaki K: Dual function of an Arabidopsis transcription factor DREB2A 
in water-stress-responsive and heat-stress-responsive gene expression. Proc Natl Acad Sci USA 2006, 103:18822-18827.

46. Mooney S, Hellmann H: Vitamin B6: Killing two birds with one stone? Phytochemistry 2010, 71:495-501.

47. Raschke M, Boycheva S, Crevecoeur M, Nunes-Nesi A, Witt S, Fernie AR, Amrhein N, Fitzpatrick TB: Enhanced levels of vitamin B(6) increase aerial organ size and positively affect stress tolerance in Arabidopsis. Plant J 2011, 66:414-432.

48. Tamura N, Yoshida T, Tanaka A, Sasaki R, Bando A, Toh S, Lepiniec L, Kawakami N: Isolation and characterization of high temperature-resistant germination mutants of Arabidopsis thaliana. Plant Cell Physiol 2006, 47:1081-1094.

49. Yoshioka T, Endo T, Satoh S: Restoration of seed germination at supraoptimal temperatures by fluridone, an inhibitor of abscisic acid biosynthesis. Plant Cell Physiol 1998, 39:307-312.

50. Gonai T, Kawahara S, Tougou M, Satoh S, Hashiba T, Hirai N, Kawaide H, Kamiya Y, Yoshioka T: Abscisic acid in the thermoinhibition of lettuce seed germination and enhancement of its catabolism by gibberellin. $J$ Exp Bot 2004, 55:111-118.

51. Cadman CS, Toorop PE, Hilhorst HW, Finch-Savage WE: Gene expression profiles of Arabidopsis Cvi seeds during dormancy cycling indicate a common underlying dormancy control mechanism. Plant J 2006, 5:805-822.

52. Leymarie J, Robayo-Romero ME, Gendreau E, Benech-Arnold RL, Corbineau F: Involvement of ABA in induction of secondary dormancy in barley (Hordeum vulgare L.) seeds. Plant Cell Physiol 2008, 49:1830-1838.

53. Larkindale J, Hall JD, Knight MR, Vierling E: Heat stress phenotypes of Arabidopsis mutants implicate multiple signaling pathways in the acquisition of thermotolerance. Plant Physiol 2005, 138:882-897.

54. Ma Y, Szostkiewicz I, Korte A, Moes D, Yang Y, Christmann A, Grill E: Regulators of PP2C phosphatase activity function as abscisic acid sensors. Science 2009, 324:1064-1068.

55. Park SY, Fung P, Nishimura N, Jensen DR, Fujii H, Zhao Y, Lumba $S$, Santiago J, Rodrigues A, Chow TF, Alfred SE, Bonetta D, Finkelstein R, Provart NJ, Desveaux D, Rodriguez PL, McCourt P, Zhu J-K, Schroeder JI, Volkman BF, Cutler SR: Abscisic acid inhibits type $2 \mathrm{C}$ protein phosphatases via the PYR/PYL family of START proteins. Science 2009, 324:1068-1071.

56. McGinnis KM, Thomas SG, Soule JD, Strader LC, Zale JM, Sun T-P, Steber CM: The Arabidopsis SLEEPY gene encodes a putative F-box subunit of an SCF E3 ubiquitin ligase. Plant Cell 2003, 15:1120-1130.

57. Dill A, Thomas SG, Hu J, Steber CM, Sun TP: The Arabidops F-box protein SLEEPY1 targets gibberellin signaling repressors for gibberellin-induced degradation. Plant Cell 2004, 16:1392-1405.

58. Griffiths J, Murase K, Rieu I, Zentella R, Zhang ZL, Powers SJ, Gong F, Phillips AL, Hedden P, Sun TP, Thomas SG: Genetic characterization and functional analysis of the GID1 gibberellin receptors in Arabidopsis. Plant Cell 2006, 12:3399-3414.

59. Ariizumi T, Murase K, Sun TP, Steber CM: Proteolysis-independent downregulation of DELLA repression in Arabidopsis by the gibberellin receptor GIBBERELLIN INSENSITIVE DWARF1. Plant Cell 2008, 9:2447-2459.

60. Goda H, Sasaki E, Akiyama K, Maruyama-Nakashita A, Nakabayashi K, Li W, Ogawa M, Yamauchi Y, Preston J, Aoki K, Kiba T, Takatsuto S, Fujioka S, Asami T, Nakano T, Kato H, Mizuno T, Sakakibara H, Yamaguchi S, Nambara E, Kamiya Y, Takahashi H, Hirai MY, Sakurai T, Shinozaki K, Saito K, Yoshida S, Shimada Y: The AtGenExpress hormone and chemical treatment data set: experimental design, data evaluation, model data analysis and data access. Plant J 2008, 55:526-542

61. Lopez-Molina L, Mongrand S, McLachin DT, Chait BT, Chua NH: ABI5 acts downstream of $A B I 3$ to execute an $A B A$-dependent growth arrest during germination. Plant J 2002, 32:317-328.

62. Kosová K, Vitámvás P, Práśil IT, Renaut J: Plant proteome changes under abiotic stress-contribution of proteomics studies to understanding plant stress response. J Proteomics 2011, 74:1301-1322.

63. Rizhsky L, Liang H, Shuman J, Shulaev V, Davletova S, Mittler R: When defense pathways collide. The response of Arabidopsis to a combination of drought and heat stress. Plant Physiol 2004, 134:1683-1696.

64. Lim CJ, Yang KA, Hong JK, Choi JS, Yun DJ, Hong JC, Chung WS, Lee SY, Cho MJ, Lim CO: Gene expression profiles during heat acclimation in Arabidopsis thaliana suspension-culture cells. J Plant Res 2006, 119:373-383.
65. Kilian J, Whitehead D, Horak J, Wanke D, Weinl S, Batistic O, D'Angelo C, Bornberg-Bauer E, Kudla J, Harter K: The AtGenExpress global stress expression data set: protocols, evaluation and model data analysis of UV-B light, drought and cold stress responses. Plant J 2007, 50:347-363.

66. Eisen MB, Spellman PT, Brown PO, Botstein D: Cluster analysis and display of genome-wide expression patterns. Proc Natl Acad Sci USA 1998, 95:14863-14868.

67. Toufighi K, Brady SM, Austin R, Ly E, Provart NJ: The Botany Array Resource: e-Northerns, Expression Angling, and promoter analyses. Plant J 2005, 43:153-163

68. Gentleman RC, Carey VJ, Bates DM, Bolstad B, Dettling M, Dudoit S, Ellis B, Gautier L, Ge Y, Gentry J, Hornik K, Hothorn T, Huber W, lacus S, Irizarry R, Leisch F, Li C, Maechler M, Rossini AJ, Sawitzki G, Smith C, Smyth G, Tierney L, Yang JY, Zhang J: Bioconductor: open software development for computational biology and bioinformatics. Genome Biol 2004, 5:R80.

doi:10.1186/1471-2229-12-15

Cite this article as: Chiu et al:: The role of the Arabidopsis FUSCA3 transcription factor during inhibition of seed germination at high temperature. BMC Plant Biology 2012 12:15.

\section{Submit your next manuscript to BioMed Central and take full advantage of:}

- Convenient online submission

- Thorough peer review

- No space constraints or color figure charges

- Immediate publication on acceptance

- Inclusion in PubMed, CAS, Scopus and Google Scholar

- Research which is freely available for redistribution 